XIJIN LU, M.S.

E-mail: 237956843@qq.com

CHANGXI MA, Ph.D. ${ }^{1}$

(Corresponding Author)

E-mail: machangxi@mail.lzjtu.cn

${ }^{1}$ School of Traffic and Transportation

Lanzhou Jiaotong University

Lanzhou 730070, China
Transport Economics Original Scientific Paper Submitted: 12 June 2020

Accepted: 12 Feb. 2021

DOI: $10.7307 /$ ptt.v33i5.3633

\title{
THE IMPACT OF INTER-CITY TRAFFIC RESTRICTION ON COVID-19 TRANSMISSION FROM SPATIAL ECONOMETRIC PERSPECTIVE
}

\begin{abstract}
The aim of this paper is to conduct a spatial correlation study of virus transmission in the Hubei province, China. The number of confirmed COVID-19 cases released by the National Health and Construction Commission, the traffic flow data provided by Baidu migration, and the current situation of Wuhan intercity traffic were collected. The Moran's I test shows that there is a positive spatial correlation between the 17 cities in the Hubei province. The result of Moran's I test also shows that four different policies to restrict inter-city traffic can be issued for the four types of cities. The ordinary least squares regression, spatial lag model, spatial error model, and spatial lag error model were built. Based on the analysis of the spatial lag error model, whose goodness of fit is the highest among the four models, it can be concluded that the speed of COVID-19 spread within a certain region is not only related to the current infection itself but also associated with the scale of the infection in the surrounding area. Thus, the spill-over effect of the COVID-19 is also presented. This paper bridges inter-city traffic and spatial economics, provides a theoretical contribution, and verifies the necessity of a lockdown from an empirical point of view.
\end{abstract}

\section{KEYWORDS}

COVID-19; inter-city traffic; spatial lag error model; Moran's I test.

\section{INTRODUCTION}

In December 2019, viral pneumonia with unknown cause suddenly appeared in Wuhan City, Hubei province and was subsequently confirmed to be a type of novel coronavirus. National Health Commission of China declared it a category B infectious disease on 20 January 2020, and adopted appropriate measures to prevent and control this category of infectious diseases [1]. On 11 February 2020, the World Health Organisation (WHO) named COVID-19 a novel coronavirus-infected pneumonia [2] for the first time and declared a COVID-19 pandemic on 11 March 2020 [3].

On 23 January 2020, just as the Chinese Lunar New Year was approaching, millions of migrant workers started to return to their hometowns, which is the largest transportation trip each year, known as the "Spring Festival travel rush". According to the Ministry of Transport, 2.98 billion trips were made during the Spring Festival travel rush on 1 March 2019. Among them, 410 million passenger trips were carried by railways, 2.46 billion passengers by roadways, 41 million passengers by water, and 73 million passengers by civil aviation. Therefore, the Spring Festival travel rush is called "the largest population movement in the world". Affected by the epidemic, the 2020 Spring Festival experienced a 45 percent drop in passenger traffic within 40 days. From 25 January to 14 February, a total of 283 million passengers were carried across the country, and most of them were visiting relatives or migrant workers returning home from work. As we all know, COVID-19 conforms to the basic transmission mechanism of airborne infectious diseases and is mainly transmitted by contact and droplets [3]. As a high-density personnel carrier, transportation provides a potential environment for the spread of COVID-19 [4]. In order to prevent the epidemic from further worsening and reduce the losses, the local government took the sternest measures. From 10:00 a.m. on 23 January 2020, all the exit corridors from Wuhan were officially closed. The urban bus, 
subway, ferry, and long-distance passenger operations were suspended, and the citizens were not allowed to leave Wuhan without special reasons [5].

Current studies on COVID-19 have focused on five aspects: epidemiological characteristics analysis based on statistics [6], virus evolution based on gene comparative analysis [7], pathogenic mechanism analysis based on structural biology [8], infection number prediction based on system dynamics [9], and epidemic emergency management and control [10-12]. Among them, many transportation-related control measures are proposed, such as travel restrictions, telecommuting, bus route re-routing, and so on [13-15].

China's economy has grown rapidly in recent years and it is gradually becoming a transportation powerhouse, thus the demand for people to travel has correspondingly expanded. As a result, there are more and more modes of transportation, such as trains, high-speed trains, subways, light rail, ride-hailing, etc. making transportation more and more convenient. As the travel cost becomes lower, the boundaries of work and life activities are no longer in line with the administrative boundaries. Commuting between cities is becoming more common, and population movement has become a condition that cannot be ignored in any aspect. At this time, as we analyse the epidemic scale, if we only consider the number of people diagnosed and the number of people likely to be infected in a single city, but the floating population caused by inter-city traffic is not accounted into the model as an explanatory variable, its influence will fall into the residual term and bring spatial correlation.

The impact of transportation on the spread of infectious diseases has been a concern for a long time. Scholars believe that human interaction and mobility will affect the spread of infectious diseases. The analysis on the diffusion mechanism of public health emergencies shows that, under a certain intensity of prevention and control, simultaneous restriction of inter-city traffic and isolation measures are more effective than isolation measure alone, and the time taken to control the spread of the epidemic is reduced from about 10 days to about 3 days [16]. SARS appeared in 2003 and the H1N1 epidemic occurred in 2009, which verifies that the regular flow behaviour of humans affect the spread of disease [17]. Moreover, it was found in a space epidemiological study that tuberculosis, SARS, and influenza are closely related to airborne transmission [18].
Respiratory infectious diseases are the most affected by population movements. Among them, respiratory droplet transmission and contact transmission are the main routes of transmission of the novel coronavirus [19]. It is pointed out that under certain prevention and control intensity, it is better to take measures to restrict population movement and isolation at the same time [20]. When a major outbreak occurs, the emergency response mechanism should be activated in the urban public transport system [21]. The analysis of 1947 confirmed COVID-19 cases in 315 transportation neighbourhoods reached the conclusion that urban spatial elements are not only associated with non-communicable diseases, but also significantly associated with infectious diseases [22]. To sum up, there is a clear understanding of the mechanism of COVID-19, but there is still a lack of empirical studies to analyse how inter-city traffic affects the spread of the COVID-19. Therefore, spatial econometrics is introduced.

Spatial econometric theory is a branch of econometrics that began to appear in the 1970s and 1980s. Spatial econometrics is a model method that considers the spatial effect of economic variables, namely the spatial correlation, and carries out a series of model setting, estimation, testing, and prediction [23]. The essence of spatial econometrics is about economy, so it is widely used in the discussion of regional economic analysis [24-26], and is of great importance for investigating the relationship between the economy and the influence of other geographical factors. Moreover, spatial econometrics has been used to explore social issues, such as the relationship between geographic location, structural characteristics, the pricing of short-term rentals [27], and the relationship between forest cover and the geographic and socio-economic indicators that drive deforestation [28]. Also, spatial econometrics can be applied to nature and biology [29]. More importantly, spatial econometric modelling is used to explore the relationship between infectious diseases and other geographic influences, and similar studies have been done by previous generations [30-33].

Therefore, the real number of confirmed cases of COVID-19 is employed in each city of the Hubei province, so as to test whether the spread of the epidemic is spatially autocorrelated using the Moran's I test. Furthermore, the ordinary least square model, spatial lag model, spatial error model, and 
spatial lag error model are established to analyse the influence of inter-city traffic on the outbreak of COVID-19 from the spatial perspective.

This paper is organised as follows. Section 2 briefly introduces the current situation of Wuhan's inter-city traffic. Section 3 shows all the data related, and explains the concepts of the Moran's I test and the four spatial econometric models. Section 4 draws conclusions and discusses the need to restrict traffic during the epidemic by showing an example of the epidemic scale in Hubei cities. The main conclusions are summarised in Section 5.

\section{INTER-CITY TRAFFIC IN WUHAN}

Wuhan is the capital city of the Hubei Province, which is closely connected to other cities. In the Hubei province, Wuhan has a strong comprehensive connection with Xiaogan, Huanggang, Ezhou, Xiangyang, and Jingzhou. The time required to travel from Wuhan to other cities by various means of transportation is shown in Table 1.

Research shows that the ventilation coefficient and personnel spacing are important parameters to reduce the risk of infection in addition to masks. Under the maximum air change coefficient, per capita ventilation capacity of high-speed train, bus, and other transportation tools all reach about $30 \mathrm{~m}^{3} / \mathrm{h}$, which is equivalent to the basic requirements of the indoor ventilation standard and is not enough to cause the spread of the virus in a large area. However, the air change coefficient of ordinary trains is relatively small per capita, so direct and close contact between people can easily cause wide spread of the virus. Due to the close geographical distance between cities in the Hubei province, people generally choose high-speed railway, regular train, private car, and long-distance bus as transportation means. According to the information, rail travel accounts for about $65 \%$ and road travel accounts for about $35 \%$ within the $\mathrm{Hu}-$ bei province [34].

The spread of the virus transmission varies depending on the environment of the various modes of transport. Based on the definition of susceptibility in epidemiology, a concept of transport susceptibility is put forward, which refers to the probability that the passengers will come into contact with a random infected person by taking a transport vehicle. There are some differences in the susceptibility of various transportation modes. The susceptibility of ordinary trains was $23.2 \%$, while the

Table 1 - Various inter-city transportation modes

\begin{tabular}{|c|c|c|c|c|}
\hline \multirow{2}{*}{ City } & \multirow{2}{*}{ Distance $[\mathrm{km}]$} & \multicolumn{3}{|c|}{ Time $[\mathrm{h}]$} \\
\hline & & Private cars & Ordinary train & High-speed train \\
\hline Xiaogan & 62.35 & 1.36 & 0.8 & 0.42 \\
\hline Huanggang & 74.29 & 1.37 & - & 0.52 \\
\hline Ezhou & 78.8 & 1.41 & 0.9 & 0.37 \\
\hline Xiantao & 103.19 & 1.68 & 1 & 0.58 \\
\hline Huangshi & 97.34 & 1.79 & 1.17 & 0.5 \\
\hline Xianning & 93.61 & 1.85 & 0.7 & 0.4 \\
\hline Tianmen & 142.11 & 2.01 & 1.51 & 0.58 \\
\hline Suizhou & 170.06 & 2.07 & 1.83 & 0.82 \\
\hline Qianjiang & 159.12 & 2.25 & - & 0.85 \\
\hline Jingzhou & 159.12 & 2.91 & 1.49 & 1.22 \\
\hline Jingmen & 239.6 & 3.15 & 3.49 & - \\
\hline Shennongjia & 473.8 & 7.15 & & \\
\hline Enshi & 521.8 & 7.17 & 8.42 & 3.51 \\
\hline Xiangyang & 304.7 & 3.93 & 2.6 & 1.2 \\
\hline Yichang & 325.9 & 4.18 & 2.13 & 1.72 \\
\hline Shiyan & 452.5 & 5.57 & 4.47 & 1.95 \\
\hline Huangshi & 100.2 & 1.62 & 1.17 & 0.5 \\
\hline
\end{tabular}


risk of susceptibility of long-distance buses, private cars, and other transportation modes was over $10 \%$, which is relatively high [35].

In summary, ordinary train travel is the most common mode of transportation in the Hubei province, and it is also the easiest way to spread the virus.

\section{DATA SOURCES AND METHODS}

\subsection{Data sources}

In this paper, the cumulative number of COVID-19 cases in 17 prefecture-level cities in the Hubei province on 23 January, the day of the lockdown, was chosen as the explanatory variable $x_{1}^{\prime}$, whereas 23 January was chosen as the object of observation since before that the inter-city traffic was large, but after that the entry and exit of residents were restricted, which is a time node that can highlight the difference. In addition, according to Li et al. published in the New England Journal of Medicine on 20 February 2020 [36], the basic reproduction number of the coronavirus before seal off $R_{0}$ was 4.38 . The basic reproduction number means that one patient will on average infect another 4.38 persons, without external intervention and lack of immunity. So 4.38 times the number of confirmed cases is the number of suspected carriers of the virus $x_{1}^{\prime \prime}$. The sum of $x_{1}^{\prime}$ and $x_{1}^{\prime \prime}$ can reflect the number of people infected with the virus in a prefecture-level city in the Hubei province before the city was sealed off, making it that $x_{1} . x_{1}$ can be considered as the scale of infection within a prefecture-level city in the Hubei province without inter-city traffic. In addition, according to the Baidu Migration statistics, a total of 5.154 million people moved out of Wuhan before the city was locked down, of which $70 \%$ moved to other cities in the Hubei province, as shown in Figure 1.

It is assumed that infected individuals are randomly dispersed within the city and that infected individuals have the same probability of leaving the city as non-infected individuals. The number of floating people with the virus in each city is $x_{2}$ and the equation for calculating the number of floating people with the virus in each city is:

$x_{2}=$ number of people infected before the closure of the city $x_{1}$

$\times$ number of floating population / number of permanent resident

where $x_{2}$ reflects the scale of the epidemic caused by floating people under no restrictions of inter-city traffic. The team from the Sun Yat-sen University also verified that the average incubation period for COVID-19 is 4.8 days [36]. Thus, the number of new diagnoses in the five days after the city closure can still be considered as a result of the unrestricted inter-city traffic before the lockdown, so the number of new diagnoses in these five days can reflect the impact of inter-city traffic on the virus outbreak. In view of the statements above, the cumulative number of new diagnoses in each city from 23 January to 29 January was chosen as the explanatory variable $y$.

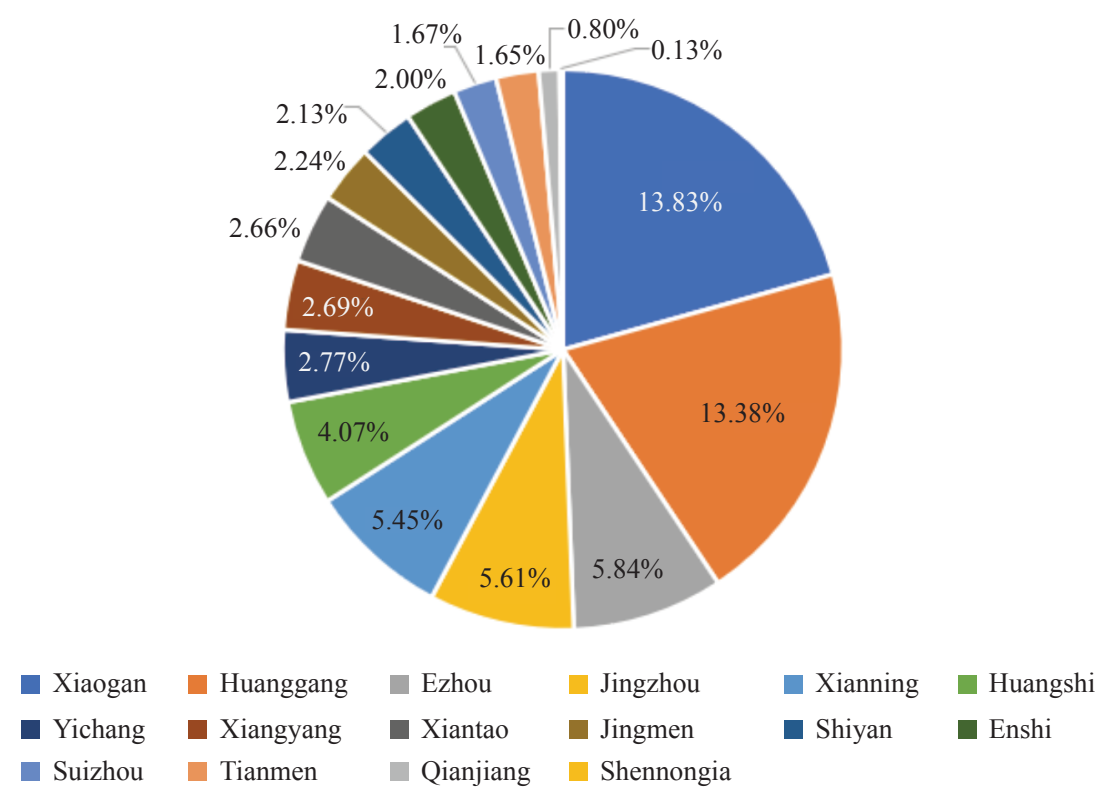

Figure 1 - Proportion of population mobility in each surrounding city 
Table 2 - Data involved

\begin{tabular}{||c|c|c|c|c|c|c|c|c|c||}
\hline City & $x_{1}^{\prime}$ & $x_{1}^{\prime \prime}$ & $x_{1}$ & $\ln x_{1}$ & $\begin{array}{c}\text { Permanent } \\
\text { population }\end{array}$ & $\begin{array}{c}\text { Floating } \\
\text { population }\end{array}$ & $x_{2}$ & $\ln x_{2}$ & $\ln y$ \\
\hline \hline Wuhan & 618 & 2707 & 3325 & 8.11 & $11,081,000$ & 213,000 & 64 & 4.16 & 7.61 \\
\hline Huangshi & 31 & 136 & 167 & 5.12 & $2,689,300$ & 257,700 & 16 & 2.77 & 4.91 \\
\hline Shiyan & 20 & 88 & 108 & 4.68 & $3,406,000$ & 154,620 & 5 & 1.61 & 4.86 \\
\hline Jingzhou & 33 & 145 & 178 & 5.18 & $6,410,000$ & 463,860 & 13 & 2.56 & 5.23 \\
\hline Yichang & 20 & 88 & 108 & 4.68 & $4,169,200$ & 206,160 & 5 & 1.61 & 4.99 \\
\hline Xiangyang & 2 & 9 & 11 & 2.40 & $6,050,000$ & 309,240 & 1 & 0.00 & 5.64 \\
\hline Ezhou & 1 & 5 & 6 & 1.79 & $1,076,900$ & 309,240 & 2 & 0.69 & 5.23 \\
\hline Jingmen & 38 & 167 & 205 & 5.32 & $3,000,000$ & 257,700 & 18 & 2.89 & 5.24 \\
\hline Huanggang & 122 & 535 & 657 & 6.49 & $7,500,000$ & 979,260 & 86 & 4.45 & 6.11 \\
\hline Xiaogan & 55 & 241 & 296 & 5.69 & $5,300,000$ & $1,030,800$ & 58 & 4.06 & 6.18 \\
\hline Xianning & 43 & 189 & 232 & 5.45 & $2,535,100$ & 360,780 & 33 & 3.50 & 4.81 \\
\hline Enshi & 17 & 75 & 92 & 4.52 & $4,026,100$ & 154,620 & 4 & 1.39 & 4.06 \\
\hline Suizhou & 36 & 158 & 194 & 5.27 & $2,216,700$ & 206,160 & 18 & 2.89 & 5.25 \\
\hline Shennongjia & 1 & 5 & 6 & 1.79 & 76,700 & 5,154 & 1 & 0.00 & 1.79 \\
\hline Qianjiang & 5 & 22 & 27 & 3.30 & 962,000 & 103,080 & 3 & 1.10 & 1.94 \\
\hline Xiantao & 11 & 49 & 60 & 4.09 & $1,563,500$ & 206,160 & 8 & 2.08 & 4.36 \\
\hline Tianmen & 5 & 22 & 27 & 3.30 & $1,609,200$ & 154,620 & 3 & 1.10 & 4.12 \\
\hline
\end{tabular}

In order to reduce the heteroscedasticity of the data and study the growth trend of the number of infected people, the natural logarithm of the data was taken to highlight the elasticity of the data without changing the data attributes. Since $x$ is the number of people, it is rounded up. All the data covered in this article are shown in the Table 2.

\subsection{Method}

Spatial econometrics makes up for the spatial correlation and spatial heterogeneity caused by the proximity of a geographical space. The parameterisation of spatial structure can test the relationship, direction, and intensity of the interaction among control variables more accurately. Considering COVID-19 as a shock to Wuhan, which inevitably affects other cities due to inter-city traffic, spatial econometrics was introduced to study the spatial correlation of the epidemic transmission.

\section{Moran's I}

Spatial econometrics holds that the economic growth of a region is often spatially interdependent on the economic growth of its surrounding regions. When an impact occurs in one region, it will have a spillover, which would affect the surrounding regions. There are many methods to measure this spa- tial autocorrelation, and the most commonly used is Moran's I test. Moran's I ranges from -1 to 1 , where the value -1 represents a negative spatial correlation and 1 represents a positive spatial correlation. If two adjacent regions have similar characteristics, the I statistic tends to be positive and vice versa. According to Anselin [37], Moran's I is:

$$
I=\left(\frac{n}{s_{0}}\right) \frac{\sum_{i=1}^{n} \sum_{j=1}^{n} w_{i j} x_{i} x_{j}}{\sum_{i=1}^{n} x_{i}^{2}}
$$

where $n$ is the number of cities included in the analysis, $w_{i j}$ is the element of spatial weight matrix $W$, $x_{i}, x_{j}$, respectively, represent the deviation in $i$ and $j$ variables, and $s_{0}$ is the standardisation factor, being equal to the sum of the elements of the weight matrix $W$.

$W$ is an important component of spatial modeling and an important tool for quantifying spatial dependencies between observations, usually expressed as an $\mathrm{N}$-order symmetric non-negative matrix, in Equation 3, in which the elements represent the connection between two regions, and this connection is exogenous information, set according to the actual situation.

$W=\left[\begin{array}{ccc}w_{11} & \cdots & w_{1 n} \\ \vdots & \ddots & \vdots \\ w_{n 1} & \cdots & w_{n n}\end{array}\right]$ 
The spatial weight matrix is generally divided into two categories, one is the Contiguity Weight Matrix and the other is the Distance Weight Matrix. Different spatial weight matrices are chosen due to the different definitions of inter-regional interactions. Tobler's first law of geography states that adjacent units exhibit a higher degree of spatial dependence than the geographically distant units [38]. This is the concept of diffusion of friction in space. Therefore, the spatial weight matrix in this paper takes the reciprocal of the distance between 17 cities, which means that the spatial dependence of the observation areas decreases with the increase of the interregional distance.

$w_{i j}=1 / d_{i j}$

To measure the average impact, the spatial weight matrix is also standardised, which means that the sum of each row of elements in the matrix is equal to 1 .

$w_{i j}^{\prime}=w_{i j} / \sum_{j=1}^{n} w_{i j}$

\section{Spatial econometric model}

Spatial Lag Model (SLM) reflects that the regional economic behaviour is influenced by the behaviour of other interdependent regions, and has nothing to do with the indirect influence of exogenous explanatory variables that may be interdependent. The model can be described as follows:

$Y=\rho W Y+X \beta+\varepsilon$

if $(I-\rho W)^{-1}$ exists, Equation 6 can be simplified as:

$Y=(I-\rho W)^{-1}(\alpha+\beta X+\varepsilon)$

where $\rho$ is the spatial regression correlation coefficient, its economic meaning is the intensity of cross-regional spillover (spatial spillover), $\alpha$ is the constant, $\beta$ reflects the effect of independent variables on dependent variable, $\varepsilon$ is the random error vector.

Equation 7 clearly describes that in the case of the COVID-19 outbreak in Wuhan, the transmission is also affected by the scale of the epidemic in other surrounding cities through the spatial multiplier effect $(I-\rho W)^{-1}$. Spatial lag model can indicate the direct influence between the explained variables in different regions.

To address the question of how inter-city traffic affects the transmission of COVID-19, in this paper, the spatial lag model is written as follows:

$$
L N Y=\rho W L N Y+L N X_{1} \beta_{1}+L N X_{2} \beta_{2}+\varepsilon
$$

Equation 8 reveals that the number of new diagnoses on 29 January is determined by four factors. The first is the number of confirmed cases in surrounding cities, that is, the spatial spillovers brought by inter-city traffic. The second is the number of confirmed cases in this region on 23 January. The third is the floating population brought by inter-city traffic and the fourth is the random error term.

Spatial Error Model (SEM) reflects that the regional economic behaviour is affected by the random error shock of the interdependence of other regions. The explained variables also depend on a set of local characteristics observed in the regional economic behaviour and some important variables (error terms) that are ignored in the geographic space. Thus the model can be expressed as follows:

$Y=X \beta+\mu$

$\mu=\lambda W \mu+\varepsilon$

where $\lambda$ is the spatial error term regression coefficient, which indicates that the spatial error spillover effect of the error term of the sample observation is measured. If $(I-\lambda W)^{-1}$, the above equation can be simplified as follows:

$Y=\alpha+X \beta+(I-\lambda W)^{-1} \varepsilon$

To address the question of how inter-city traffic affects the transmission of COVID-19, the spatial error model is written as follows:

$$
L N Y=L N X_{1} \beta_{1}+L N X_{2} \beta_{1}+\mu
$$

$\mu=\lambda W \mu+\varepsilon$

Equations 12 and 13 suggest that the number of new diagnoses on 29 January is determined by three factors. The first is the number of confirmed cases on 23 January, the second is the number of floating population caused by inter-city traffic, and $\mu$ is the error term. The error term includes two aspects, the first is the influence of super-spreaders in the surrounding area, and $\varepsilon$ is the random error term.

The difference between spatial lag model and spatial error model lies in that the former reflects spatial substantive correlation, while the latter gives spatial indirect correlation.

If only the SLM or the SEM is employed, the estimated results will be biased. Based on the spatial lag model and spatial error model, the Spatial Lag Error Model (SLEM) is proposed, which not only 
considers the impact of the number of infected people in the surrounding areas, but also the error of the number of infected people in the surrounding areas.

The mathematical expression of the spatial lag error model is as follows:

$$
\begin{aligned}
& Y=\rho W Y+X \beta+\mu \\
& \mu=\lambda W \mu+\varepsilon
\end{aligned}
$$

To address the question of how inter-city traffic affects the transmission of COVID-19, the spatial lag error model is written as follows:

$$
\begin{aligned}
& L N Y=\rho W L N Y+L N X_{1} \beta_{1}+L N X_{2} \beta_{2}+\mu \\
& \mu=\lambda W \mu+\varepsilon
\end{aligned}
$$

Equations 16 and 17 indicate that the number of new diagnoses on 29 January is determined by four factors. The first is the number of confirmed cases in surrounding cities, that is, the spatial spillover effect brought by inter-city traffic; the second is the number of confirmed cases in this region on 23 January; the third is the floating population brought by inter-city traffic; and $\mu$ is the error term. The error term includes two aspects: the first is the influence of possible super spreaders in the surrounding area and $\varepsilon$ is the random error term.

The SLEM is a generalised form of the spatial lag model as well as the SEM. When $\rho=0$ and $\lambda \neq 0$, it degenerates to the spatial error model, and when $\rho \neq 0$ and $\lambda=0$, it degenerates to the SLM.

\section{RESULTS AND DISCUSSION}

Firstly, a geographic vector graphic of Hubei province using ArcGIS software was drawn, and then the GeoDa software was used to process and analyse the data. Figure 2 shows the quartile of the number of confirmed COVID-19 patients on 29 January in the Hubei province. It can be seen that the cities with the high quartile are mainly distributed in the northern part of the Hubei province. The middle quartile cities are mainly distributed in the south of the Hubei province. The low quartile cities are located in eastern and central Hubei province. And the number of cities in the three quartiles is relatively average.

To calculate the spatial correlation of the epidemic transmission among 17 cities in the Hubei province, Moran's I of lny was calculated. The scatterplot of Moran's I test and its significance after 999 times permutations are shown in Figures 3 and 4 , respectively. The horizontal coordinate represents lny, and the vertical coordinate is the corresponding value of the spatial lag. The result of Moran's I test is 0.139 , and as can be seen from Figure 4, the pseudo p-value is 0.047 , less than 0.05 , so it is signifi-

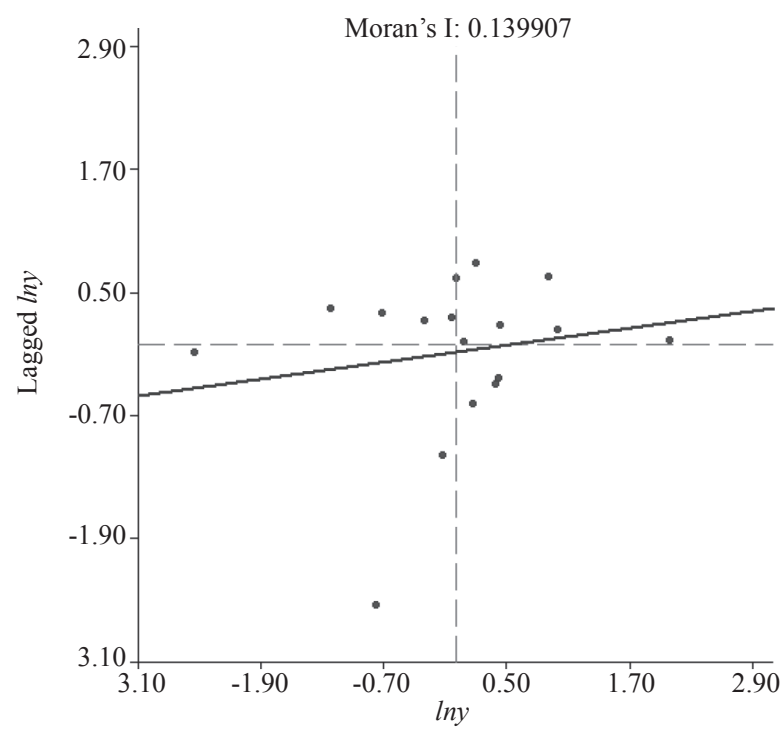

Figure 3 - Scatter diagram of Moran's I

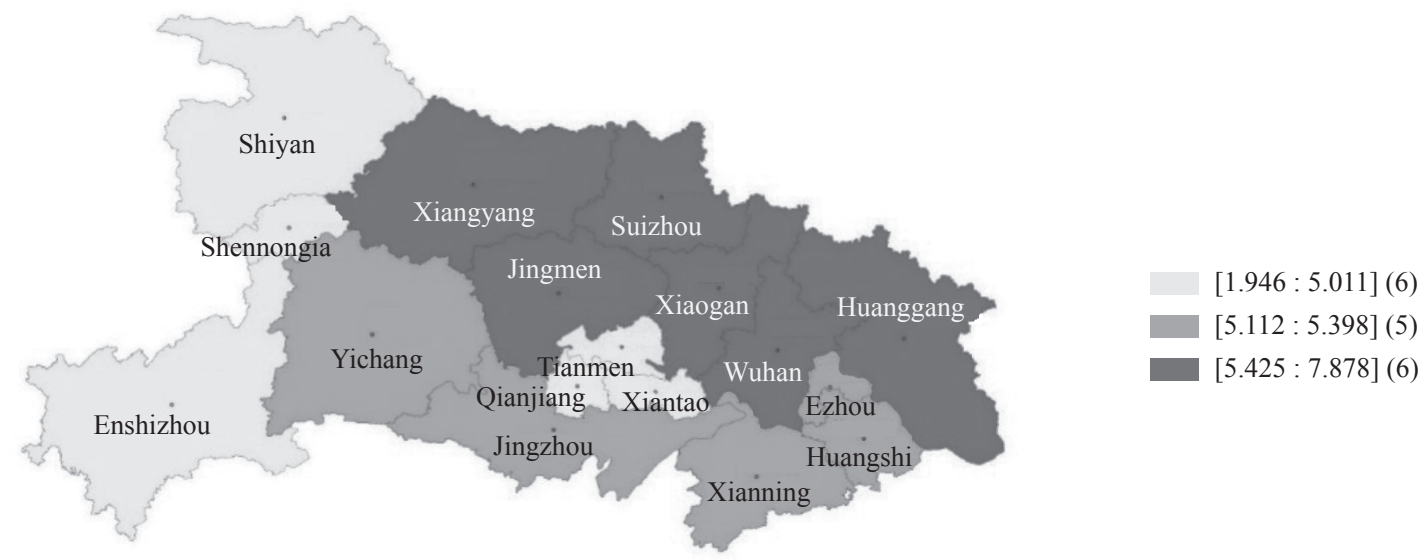

Figure 2 - The quantile of confirmed patients in the Hubei province 
Permutations: 999

Pseudo p-value: 0.047000

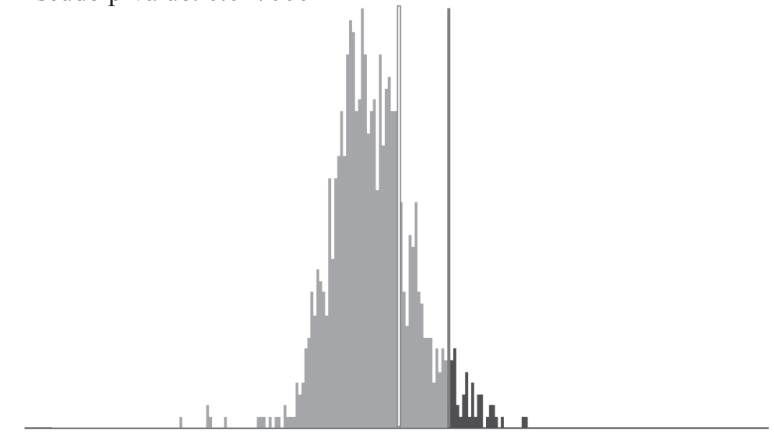

I: $0.1399 \mathrm{E}[\mathrm{I}]$ : -0.625 mean: -0.0650 sd: 0.1117 Z-value: 1.8344

Figure 4-Significance of Moran's I

cant at the $5 \%$ level. That is to say, the spread of the COVID-19 among 17 cities in the Hubei province is not simply a random distribution within cities, but has a clear positive correlation with geographical distance.

It can be seen in Figure 3 that the Moran's I scatter diagram is divided into four quadrants by two dashed lines. The two dashed lines are the mean of lny and lny lag values, respectively. The first quadrant represents the $\mathrm{H}-\mathrm{H}$ type, that is, high-infection cities are also surrounded by high-infection cities. The second quadrant represents the L-H type, that is, cities with low infection numbers are surrounded by cities with high infection numbers. The third quadrant represents the L-L type, that is, low-infection cities are surrounded by low-infection cities. The fourth quadrant represents the H-L type, that is, cities with high infection numbers are surrounded by cities with low infection numbers. In order to intuitively show the respective spatial aggregation patterns of the 17 cities, the spatial correlation patterns of all cities are given in Table 3. It can be seen from Figure 5 that the few cities with a small proportion of inflow from Wuhan, such as Shennongjia, Shiyan, and Enshizhou, have a small scale of infection. However, cities with high transport links to Wuhan, such as Ezhou, Huanggang, Xiaogan, and Jingzhou, are in the first quadrant. The government departments can issue the different policies to four different types of city. The cities in L-L can relax the inter-city traffic control, the cities in $\mathrm{H}-\mathrm{H}$ need to strengthen the inter-city traffic control, the cities in H-L need to strengthen the outflow of inter-city traffic control, and the cities in L-H need to strengthen the inflow of inter-city traffic control.

The classical Ordinary Least Squares (OLS) regression model, spatial lag model, and spatial error model are considered before the spatial lag error

Table 3 - Space-related patterns in 17 cities

\begin{tabular}{||c|c|l|c||}
\hline Quadrant & $\begin{array}{c}\text { Spatial correlation } \\
\text { mode }\end{array}$ & \multicolumn{1}{|c||}{ City } & Quantity \\
\hline \hline First quadrant & H-H & $\begin{array}{l}\text { Ezhou, Huanggang, Huangshi, Suizhou, Wuhan, Xiaogan, } \\
\text { Jingmen }\end{array}$ & 7 \\
\hline Second quadrant & L-H & Qianjiang, Xiantao, Tianmen, Xianning & 4 \\
\hline Third quadrant & L-L & Shiyan, Shennongjia forest areas, Enshi & 3 \\
\hline Fourth quadrant & H-L & Jingzhou, Xiangyang, Yichang & 3 \\
\hline
\end{tabular}

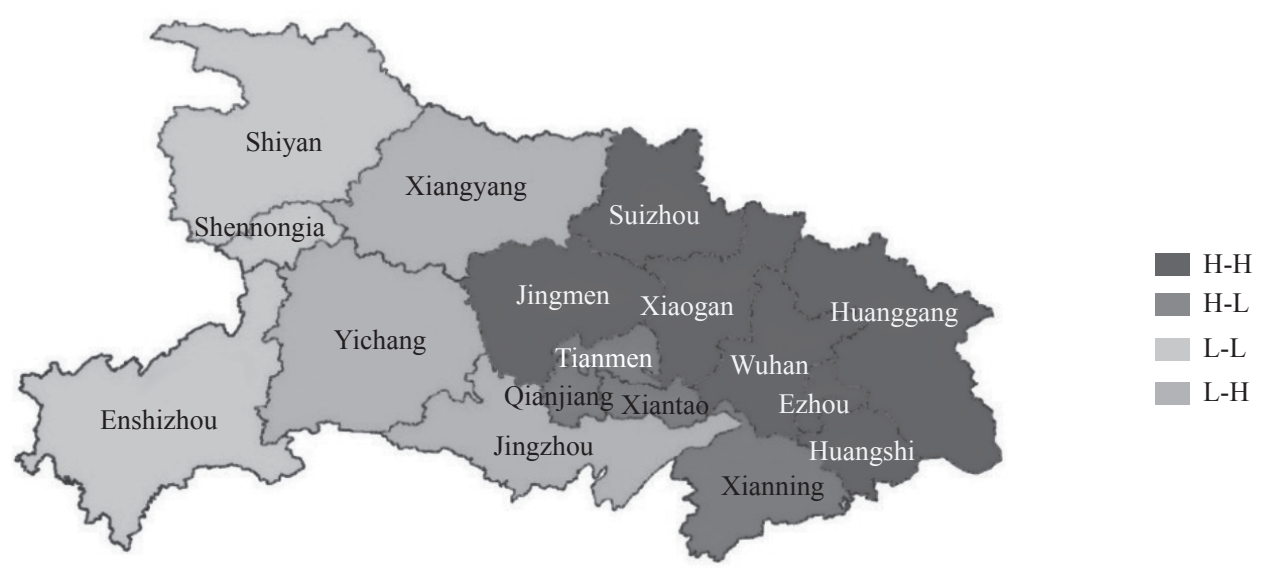

Figure 5-Spatial correlation patterns of 17 cities 
Table 4-Regression results of the four models

\begin{tabular}{|c|c|c|c|c|}
\hline Variable & OLS & SLM & SEM & SLEM \\
\hline $\ln x_{1}$ & $\begin{array}{l}1.01674 * * * \\
(0.123693)\end{array}$ & $\begin{array}{c}1.11545^{* * *} \\
(0.12681)\end{array}$ & $\begin{array}{c}1.05107 * * * \\
(0.10642)\end{array}$ & $\begin{array}{c}1.12176^{* * * *} \\
(0.1159)\end{array}$ \\
\hline $\ln x_{2}$ & $\begin{array}{c}0.08635 \\
(0.12002)\end{array}$ & $\begin{array}{l}-0.032005 \\
(0.13258)\end{array}$ & $\begin{array}{c}0.02699 \\
(0.11717)\end{array}$ & $\begin{array}{c}-0.04098 \\
(0.1162)\end{array}$ \\
\hline wlny & - & $\begin{array}{c}0.102309 * \\
(0.07731)\end{array}$ & - & $\begin{array}{c}0.00746 * * * \\
(0.00338)\end{array}$ \\
\hline$\lambda$ & - & - & $\begin{array}{c}0.36304^{*} \\
(0.303196)\end{array}$ & $\begin{array}{c}-0.192681 * * * \\
(0.402768)\end{array}$ \\
\hline constant & $\begin{array}{c}0.65531 * * * \\
(0.39046)\end{array}$ & $\begin{array}{c}-0.153729 * \\
(0.68977)\end{array}$ & $\begin{array}{c}0.638191^{* *} \\
(0.32711)\end{array}$ & $\begin{array}{c}0.147342 \\
(0.400559)\end{array}$ \\
\hline$R^{2}$ & 0.9637 & 0.9678 & 0.9663 & 0.9705 \\
\hline
\end{tabular}

Note: *** significant at the $1 \%$ level, ** significant at the $5 \%$ level, * significant at the $10 \%$ level.

model is performed. Unlike spatial econometric models, OLS regressions are ordinary least squares regressions, and spatial econometric models are maximum likelihood estimate regressions. The OLS regression is introduced to assume that the epidemic transmission status among the 17 cities in the Hubei province is independent of each other.

Table 4 lists the OLS, SLM, SEM, and SLEM regression results. It can be seen that the SLEM has the best fit compared to the OLS, SEM, and SLM model. This indicates that the number of new diagnoses on 29 January is determined by four factors as given in Equations 16 and 17.

By comparing the four models, $R^{2}$ of all four models is close to 1 , indicating that the independent variables are well chosen. In addition, $\ln x_{1}$ for all four models is very significant, implying that the number of people diagnosed on 29 January is still mainly influenced by the scale of the epidemic in their own city on 23 January. The constant terms of the OLS, SLM, and SEM model are significant in different degrees. This indicates that for these three models there is a part of the independent variable that influences the dependent variable, which leads to the correlation between the constant term and the dependent variable. The constant term of the SLEM is not significant, revealing that all relevant factors are taken into account.

According to the regression results of the SLEM, without limiting the inter-city traffic, for every percentage point increase in $\ln x_{1}$, there is a 1.12176 percentage point increase in lny. The coefficient of $w \ln y, \rho$, for every one percentage point increase, lny increases by 0.00746 points. For each percentage point $\lambda$ increase, lny decreases 0.192681 percentage points.

\section{CONCLUSIONS}

Based on the Baidu Migration data and the classic spatial econometric model, this paper investigates the impact of inter-city traffic restriction on COVID-19 transmission. The main conclusions are as follows:

1) The article shows the inter-city traffic situation of Wuhan, and the traffic susceptibility of various transportation vehicles. It is found that the ordinary train is the most common mode of transportation in the Hubei province, which is the easiest way to spread the virus. That is to say, COVID-19 is extremely easy to spread through inter-city traffic in Wuhan.

2) By using real data of confirmed cases in 17 cities respectively, and introducing the Moran's I test, it can be seen that the COVID-19 transmission is related to the geographical location and presents a positive spatial correlation. In other words, when the severity of the epidemic in a city is explored, it is not enough to consider only the number of confirmed cases in that city, but also the number of confirmed cases in the surrounding cities.

3) According to Moran's I test, 17 cities are divided into four types, namely, H-H, H-L, L-H and L-L, which respectively represent high-infection cities surrounded by high-infection cities, high-infection cities surrounded by low-infection cities, low-infection cities surrounded by 
high-infection cities, and low-infection cities surrounded by low-infection cities. This can provide the government with new ideas: for $\mathrm{H}-\mathrm{H}$-type cities, the inter-city traffic restriction should be strengthened, for H-L-type cities, they need to strengthen the outflow of inter-city traffic control, and for L-H-type cities, the inflow of inter-city traffic control should be strengthened, while for L-L-cities, they can relax the inter-city traffic restriction.

4) By comparing the OLS model, spatial error model, spatial lag model, and spatial lag error model, it is found that the spatial lag error model is well adapted, verifying that the number of new diagnoses on 29 January is determined by four factors. The first is the number of confirmed cases in surrounding cities, that is, the spatial spillover effect brought by inter-city traffic, the second is the number of confirmed cases in this region on 23 January, the third is the floating population brought by inter-city traffic, and the fourth is the error term. The error term includes two aspects: the first is the influence of possible super spreaders in the surrounding area; the second is the random error term.

5) According to the regression results of the SLEM, the main reason for the epidemic affecting a certain region is the number of local infections, but the scale of the epidemic in surrounding areas still has a small but not negligible impact on the spread of the virus.

Due to the lack of medical experience in the early stages of the epidemic, there have been many examples of diagnostic errors, which have brought some data error. Moreover, this paper did not take the neighbouring cities of the Hubei province into consideration. In addition, since the COVID-19 pandemic took place in the capital city of the Hubei province, the spatial effect of the spread was amplified to some extent, and this can be used to improve future research.

\section{ACKNOWLEDGMENTS}

This research was funded by the National Natural Science Foundation of China Grant No. 71861023, No.52062027, the Program of Humanities and Social Science of Education Ministry of China Grant No. 18YJC630118, Foundation of a Hundred Youth Talents Training Program of the Lanzhou Jiaotong University, Philosophy and Social Science Foundation of Ningbo No. G20-ZX37, and the "Double-First Class" Major Research Programs, Educational Department of Gansu Province No. GSSYLXM-04.

\section{鲁熙今, 硕士 ${ }^{1}$}

E-mail: 237956843@qq.com

马昌喜, 博士 ${ }^{1}$

E-mail: machangxi@mail.lzjtu.cn

1 兰州交通大学，交通运输学院

中国甘肃省兰州市安宁区安宁西路 88 号, 730070

空间计量视角下限制城际交通对COVID-19病毒 传播的影响

\section{摘要}

本文选取中国湖北省为研究对象, 旨在开展病 毒传播的空间相关性研究。同时, 本文收集了国家 卫生和建设委员会发布的新冠肺炎确诊人数、百度 迁徙平台提供的交通流数据以及湖北省武汉市城际 交通现状。莫兰检验表明，湖北省17个城市之间存 在正的空间相关性。另外, 莫兰检验的结果也表 明, 对于四种类型的城市, 可以出台四种不同的城 际交通限制政策。本文建立了普通最小二乘回归模 型、空间滞后模型、空间误差模型和空间滞后误差 模型。其中空间滞后误差模型是拟合度最高的模 型，基于空间滞后误差模型的分析可以得出结论，COVID-19蔓延的速度不仅是与本地区扩散规模相 关, 还与周边地区的疫情规模相关。这一点证明新 冠肺炎病毒传播存在溢出效应。本文将城际交通与 空间经济学结合起来, 提供了理论贡献, 并从实证 的角度验证了封城的必要性。

\section{关键词:}

新冠肺炎;城际交通;空间滞后误差模型; 莫兰检验

\section{REFERENCES}

[1] National Health Commission. Preventive measures against COVID-19 is class A. Available from: http:// finance.china.com.cn/news/20200121/5178840.shtml [Accessed January 2020].

[2] NationalHealthCommission.WHOhasnamedthepneumonia "COVID-19", 2020. Available from: http://world.people.com.cn/n1/2020/021 2/c1002-31582421.html [Accessed February 2020].

[3] World Health Organisation. Coronavirus disease (COVID-19) Pandemic. Available from: https://www. who.int/emergencies/diseases/novel-coronavirus-2019 [Accessed April 2020].

[4] Jin $\mathrm{Y}$, et al. A rapid advice guideline for the diagnosis and treatment of 2019 novel coronavirus (2019-nCoV) infected pneumonia (standard version). Mil Med Res. 2020;7(1): 4. DOI: 10.1186/s40779-020-0233-6

[5] Hubei Government. Wuhan COVID-19 prevention and control headquarters circular (No. 1); 2020. Available from: https://www.hubei.gov.cn/zhuanti/2020/ 
gzxxgzbd/zxtb/202001/t20200123_2014402.shtml [Accessed January 2020].

[6] Chen Z. Diffusion evolution mechanism of public health emergencies and collaborative emergency management mechanism. Ph.D. thesis. Southwest JiaoTong University; 2011.

[7] Forster P, et al. Phylogenetic network analysis of SARSCoV-2 genomes. Proceedings of the National Academy of the United States of America. 2020;117(17): 92419243. Available from: DOI: 10.1073/pnas.2004999117

[8] Yan R, et al. Structure of dimeric full-length human ACE2 in complex with B0AT1. bioRxiv. 2020. DOI: 10.1101/2020.02.17.951848

[9] Jung S, et al. Real-time estimation of the risk of death from novel coronavirus (COVID-19) infection: Inference using exported cases. Journal of Clinical Medicine. 2020;9(2): 523-535. DOI: 10.3390/jcm9020523

[10] Hendrickson C, Rilett LR. The COVID-19 pandemic and transportation engineering. Journal of Transportation Engineering Part A Systems, 2020;146(7): 01820001. DOI: 10.1061/JTEPBS.0000418

[11] Mogaji E. Impact of COVID-19 on transportation in Lagos, Nigeria. Transportation Research Interdisciplinary Perspectives. 2020;6: 100154. DOI: 10.1016/j. trip.2020.100154

[12] Bonful H, et al. Limiting spread of COVID-19 in Ghana: Compliance audit of selected transportation stations in the Greater Accra region of Ghana. PLOS ONE. 2020;15(9): e0238971-e0238971. DOI: 10.1371/journal.pone. 0238971

[13] Wang Y, Xu D, Shi L. Thoughts on urban transportation under the COVID-19 pandemic. Urban Transport of China. 2020;018(003): 88-92. DOI: 10.13813/j.cn115141/u.2020.0305

[14] Tan L, Ma C. Choice behavior of commuters' rail transit mode during the COVID-19 pandemic based on logistic model. Journal of Traffic and Transportation Engineering (English Edition). 2020. DOI: 10.1016/ j.jtte.2020.07.002

[15] Li D, Zheng L. Transportation management and planning under the COVID-19 pandemic in Wuhan. Urban Transport of China. 2020;018(003): 11-16,50. DOI: 10.13813/j.cn11-5141/u.2020.0018

[16] Epidemiology Group of Emergency Response Mechanism of New Coronavirus Pneumonia, Chinese Center for Disease Control and Prevention. Analysis of epidemiological characteristics of the 2019 Novel Coronavirus Pneumonia (COVID-19). Chinese Journal of Epidemiology.2020;41(2): 145-151. DOI: 10.3760/cma.j.issn. 0254-6450.2020.02.003

[17] Yang J. The spreading of infectious diseases with recurrent mobility of community population. Physica A. 2019;541(1): 123316. DOI: 10.1016/j.physa.2019.123316

[18] Zhou H, Hao C, Zou X. The influence of migration on the burden of and response to infectious disease threats in China: A theoretically informed review. Journal of Public Administration. 2014;4(1): 4-28,182. DOI: 10.3969/j.issn.1674-2486.2014.04.001

[19] Ren F, et al. The classification of population mobility and impact on infectious diseases. Soft Science of Health 2010;24(3): 272-275. DOI: 10.3969/j.issn.10032800.2010.03.030

[20] Ma Z, Ma Z. System dynamics of simulation of spread of major infections disease-A case study on SARS. Journal of Southwest Jiaotong University. 2011;12(1): 132-136. DOI: 10.3969/j.issn.1009-4474.2011.04.026

[21] Zhou J, et al. Unconventional prevention strategies for urban public transport in the COVID-19 epidemic: Taking Ningbo City as a case study. China Journal of Highway and Transport. 2020;33(12): 1-10. DOI: 10.13140/ RG.2.2.20856.06405

[22] $\mathrm{Li} \mathrm{W}$, et al. The impact of traffic exposure and land use patterns on the spread risk of COVID-19 at community level. China Journal of Highway and Transport. 2020;3(1): 1-17. Available from: http://kns.cnki.net/ $\mathrm{kcms} /$ detail/61.1313.U.20200721.1636.002.html

[23] Anselin L. Specification tests on the structure of interaction in spatial econometric models. Papers of the Regional Science Association.1984;54(1): 165-182. DOI: 10.1007/BF01940131

[24] Chen Y, Zhang L. Research on the effect of technique choice on Chinese provincial economic development: Based on spatial autoregressive model with autoregressive disturbances panel data model. Journal of Huaqiao University (Philosophy \& Social Sciences). 2017;3(2): 71-80. DOI: 10.3969/j.issn.1006-1398.2017.03.005

[25] Hua W. The impact of Chinese trade and investment on West African economic growth: A spatial econometrics approach. Open Journal of Applied Sciences. 2020;10(1): 142-153. DOI: 10.4236/ojapps.2020.104012

[26] Xu Y, Li A. The relationship between innovative human capital and interprovincial economic growth based on panel data model and spatial econometrics. Journal of Computational and Applied Mathematics. 2019;365: 112381. DOI: 10.1016/j.cam.2019.112381

[27] Chica-Olmo J, González-Morales JG, Zafra-Gómez JL. Effects of location on Airbnb apartment pricing in Málaga. Tourism Management. 2020;77: 1-13. DOI: 10.1016/j.tourman.2019.103981

[28] Ferrer Velasco R, Köthke M, Lippe M, Günter S. Scale and context dependency of deforestation drivers: Insights from spatial econometrics in the tropics. PLoS ONE. 2020;15(1): e0226830. DOI: 10.1371/journal. pone. 0226830

[29] Huang C. A study on floodplain inundation analysis and modelling method based on remote sensing and GIS. $\mathrm{PhD}$ thesis. East China Normal University; 2014.

[30] Yang G, Zhou X, Wang T. Spatial autocorrelation analysis of schistosomiasis cases and oncomelania snail in three provinces of the lower reach of Yangtze River. Chinese Journal of Parasitology and Parasitic Diseases. 2002;20(1): 6-9. DOI: 10.3969/j.issn.10007423.2002.01.002

[31] Wang Y, Wang C, Xia Y. Study of risk factors of endemic fluorosis in Jiangsu Province by spatial autoregressive model. Jiangsu Journal of Preventive Medicine. 2010;11: 106-109. DOI: 10.13668/ j.issn.1006-9070.2016.06.13

[32] Shen D, Ying L. Modeling the SARS epidemic in China. 
Journal of Nanjing Xiaozhuang University. 2006;11(1): 62-66. DOI: 10.3969/j.issn.1009-7902.2006.06.015

[33] Lin D, Cui Z, Zhao J. Detecting the correlation between atmosphere factors and tuberculosis incidence using spatial econometric model. Chongqingyixue. 2019;48(1): 2341-2344, 2348. DOI: 10.3969/j.issn.16718348.2019.14.001

[34] Luo M, et al. Characteristic analysis of the urban integrated transportation in Wuhan City from the perspective of big data. Geospatial Information. 2020;18(5): 1-7. DOI: $10.3969 / \mathrm{j} .1 \mathrm{ssn} .1672-4623.2020 .05 .001$

[35] Zhang Y, Wang X, Bi Q. Travel-infected susceptibility based on transmission mechanism of COVID-19. Transport Research. 2020;6(01): 73-80. DOI: 10.16503/j. cnki.2095-9931.2020.01.010

[36] Li J, et al. Estimation of the epidemic properties of the 2019 novel coronavirus: A mathematical modeling study. medRxiv. 2020. DOI: 10.2139/ssrn.3542150

[37] Anselin L, Florax RJGM. New directions in spatial econometrics: Introduction. Berlin, Heidelberg: Springer; 1995. DOI: 10.1007/978-3-642-79877-1_1

[38] Tobler WR. A computer movie simulating urban growth in the Detroit region. Economic Geography. 1970;46(3): 234-240. DOI: $10.2307 / 143141$ 